\title{
DEFORMATION PROPERTIES OF TAILOR-WELDED BLANK MADE OF DUAL PHASE STEELS
}

\author{
Alexander SCHREK ${ }^{*}$ Pavol ŠVEC*, Veronika GAJDOŠOVÁ* \\ "Faculty of Mechanical Engineering, Slovak University of Technology in Bratislava, Institute of Technologies and Materials, \\ Pionierska 15, 83102 Bratislava, Slovakia \\ alexander.schrek@stuba.sk, pavol.svec@stuba.sk, veronika.gajdosova@stuba.sk
}

received 2 November 2015, revised 18 February 2016, accepted 22 February 2016

\begin{abstract}
The paper is dedicated to forming and properties of passenger car's B-pillar reinforcement drawn from simple blank and alternatively tailor-welded blank (TWB). Drawn part is characterised by a place with a large strain, while forming process simulation did not confirm the creation of crack using the TWB consisting of dual phase HCT980X instead of previous HCT600 steel. It is because HCT980X steel has higher strength and lower ductile properties. The analysis of properties of drawn parts is focused on the simulated crash test in Dynaform software. Obtained sizes of drawn forces in simulated frame of the drawn parts and their comparison proved the possibility of the replacement the $1.2 \mathrm{~mm}$ thick simple blank from HCT600 steel with the $1 \mathrm{~mm}$ thick TWB consisting of HCT600 and HCT980X steel. The changed thickness of the simple blank caused $20 \%$ weight saving while containing the same properties of the drawn part.
\end{abstract}

Keywords: Dual Phase Steels, Tailor-Welded Blank, Drawn Part, Crash Test Simulation, Reaction Force

\section{INTRODUCTION}

In several industries (e.g. the automotive and aerospace industries), the need for lightweight and cost-effective products with exceptional performance is essential for success. Tailor welded blanks (TWBs) offer an excellent means to meet these competing and seemingly contradictory demands. They are used for forming of parts with special strength, stiffness and operational deformation properties (Kinsey and Wu, 2011; Evin and Tomáš, 2012; Bílik et al., 2015; Fracz et al., 2014; Reisgen et al., 2012). With the use of materials with different stress-strain properties or different thicknesses we can achieve higher strength and stiffness while lower weight of the drawn parts or even the whole construction (Slota et al., 2014; Evin, 2013; Fracz et al., 2013; Bílik et al, 2010; Evin et al., 2015; Merklein et al., 2014). On the other hand, these differences cause uneven material flow into the die area, which result in several forming problems, e.g. weld line displacement or sheet thickness reduction of more ductile material. These effects should be minimised in the preparation process by means of special design of forming tool or optimising of blankholder forces distribution (Sinha et al., 2013; Zhong-Qin et al., 2007; Reisgen et al., 2010).

The aim of the experiment was to analyse the manufacturing possibility and comparison of the deformation properties of the Bpillar reinforcement of the car bodywork from two types of blanks. First researched solution is simple blank made of dual phase steel and the second one is TWB consisting of dual phase steel in boundary areas and dual phase steel with significantly different (higher) stress and (lower) ductile properties in the middle area of the part. Simulation software based on finite element method (FEM) is a common solution for dealing with specifics of forming of TWBs. Dynaform was specially developed for crash testing. This paper presents the result of the experiment simulating crash test of the chosen B-pillar by the deformation tool (Padmanabhan et al., 2007; Chena et al., 2008; Groche and Metz, 2006; Daxin et al., 2008). We were evaluating the sizes and diagrams of reaction forces in simulated frames of the drawn parts in the both variants, their time dependence differences and the prediction of application possibility while decreasing weight of the car bodywork.

\section{EXPERIMENT}

The material of the real B-pillar drawn part was dual phase steel HCT600. The conditions analysis of the simple blank formability was the basis for the comparison with TWB formability.

Chemical composition and stress-strain parameters are in Tabs. 1, 2. In the simulation we used material model defined by the tensile test.

Tab. 1. Chemical composition of the steel HCT600

\begin{tabular}{|c|c|c|c|c|c|c|c|}
\hline $\begin{array}{c}\mathrm{C} \\
{[\%]}\end{array}$ & $\begin{array}{c}\mathrm{Si} \\
{[\%]}\end{array}$ & $\begin{array}{l}\mathrm{Mn} \\
{[\%]}\end{array}$ & $\begin{array}{c}\mathrm{P} \\
{[\%]}\end{array}$ & $\begin{array}{c}\mathrm{S} \\
{[\%]}\end{array}$ & $\begin{array}{c}\mathrm{Al} \\
{[\%]}\end{array}$ & $\begin{array}{c}\mathrm{N} \\
{[\%]}\end{array}$ & $\begin{array}{c}\mathrm{Cr}+\mathrm{Ni} \\
+\mathrm{Cu}[\%]\end{array}$ \\
\hline 0.12 & 0.5 & 1.4 & 0.08 & 0.008 & 0.04 & 0.009 & 1.3 \\
\hline
\end{tabular}

Tab. 2. Basic mechanical properties of steel HCT600

\begin{tabular}{|c|c|c|}
\hline $\mathrm{R}_{\mathrm{p} 0,2}[\mathrm{MPa}]$ & $\mathrm{R}_{\mathrm{m}}[\mathrm{MPa}]$ & $\mathrm{A}_{80}[\%]$ \\
\hline 390 & 650 & 26.6 \\
\hline
\end{tabular}

The blank shape (Fig. 1) was optimised while forming tool construction using Dynaform software with the aim of minimisation of strain and wall thickness reduction. Sheet thickness of simple blank was $1.2 \mathrm{~mm}$. 


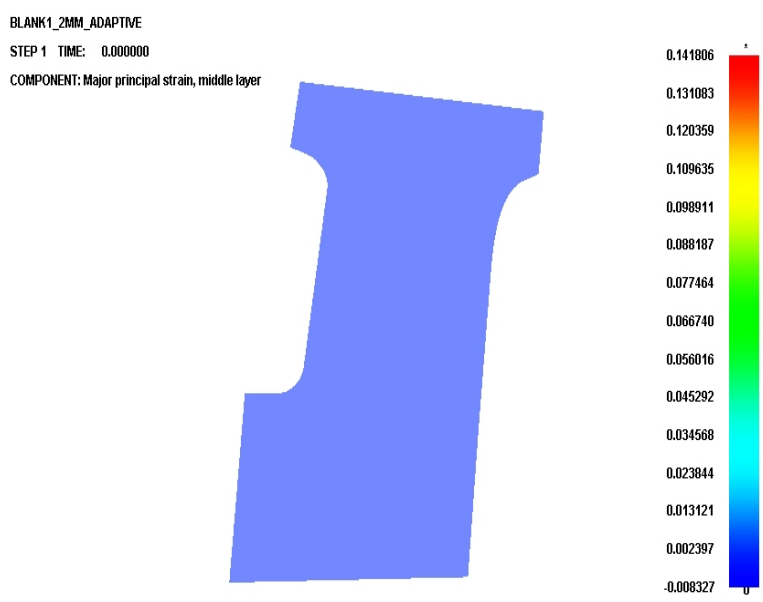

Fig. 1. Shape of the simple blank (blue colour signalised $\varphi=0$ )

Simulation of technological process of deep drawing is based on the geometry of the tool function part which is the same as the real tool used for the manufacturing of structural body part - Bpillar reinforcement. The die is the moving part with the simulated speed of $1 \mathrm{~m} / \mathrm{s}$ and die displacement of $0.5 \mathrm{~m}$. The use of such speed is a condition for the use of simulation solver, which, as a dynamic software, easily and accurately solves dynamic operations. The punch is defined as a stationary member. Model of the drawing tool is shown in Fig. 2. „Mesh scaling" or ,,velocity scaling" are used for shortening of computational time, since solver converges towards the process result faster.

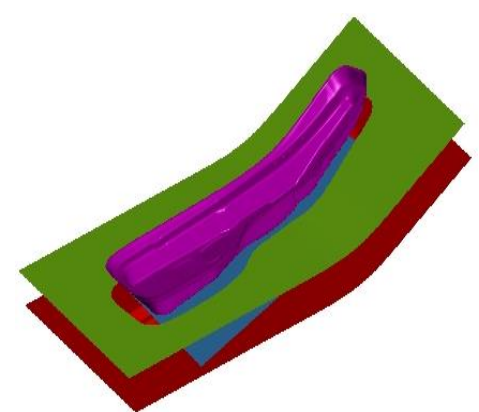

Fig. 2. Model of the drawing tool created in Dynaform software
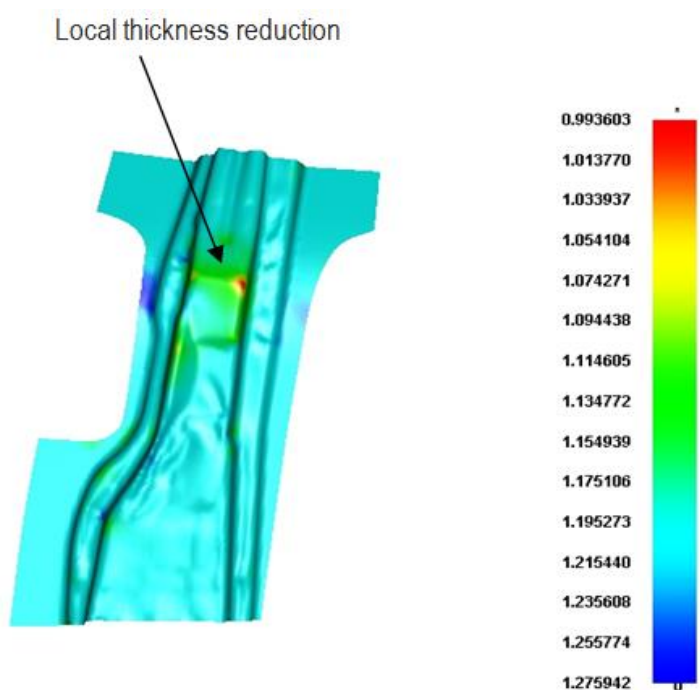

Fig. 3. Simulation of drawing of the B-pillar from the simple blank
Fig. 3 shows the example of the B-pillar reinforcement drawing simulation from the simple blank, with marked critical area with the largest strain and local thickness reduction $(-0.2 \mathrm{~mm})$. The size of the blankholder force was optimised on the value $250 \mathrm{kN}$ during the forming process.

Fig. 4 shows drawn part with the areas highlighted by color corressponding to the strain values given by FLD - diagram. By comparing the true values of logarithmic strain in critical aeras of the part to the strain values in various areas of FLD - diagram, technological safety of the operation can be obtained given by the area of limit deformations. The greatest stress concentration is shown in green, which according to the diagram in Fig. 5 is still in the safe zone, and does not cause crack of the part.

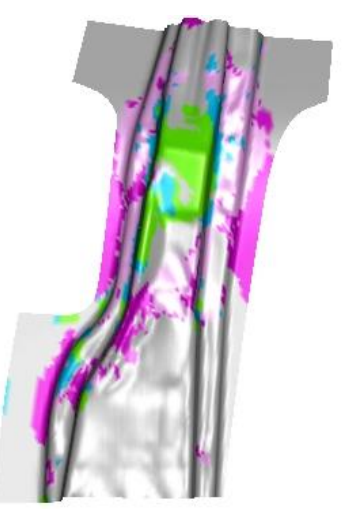

Fig. 4. B-pillar drawn from the simple blank with highlighted strain areas

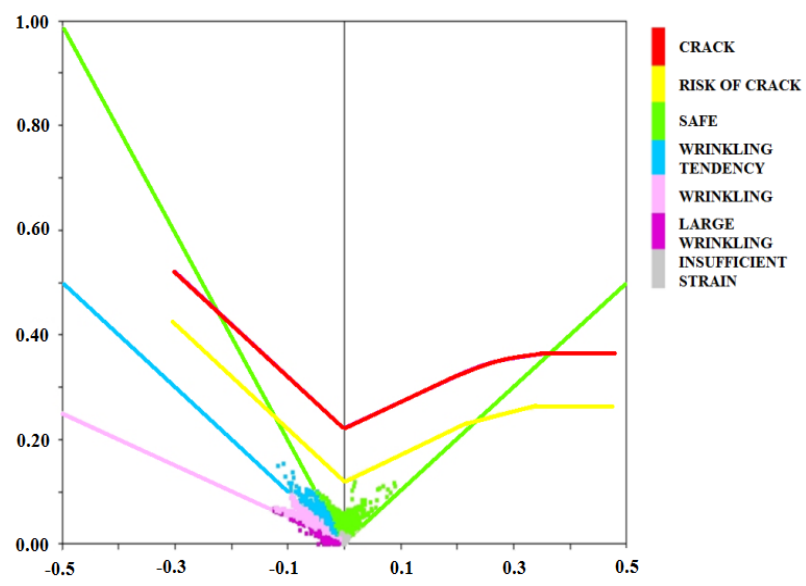

Fig. 5. Forming Limit Diagram - FLD with a color legend for the B-pillar drawn from simple blank

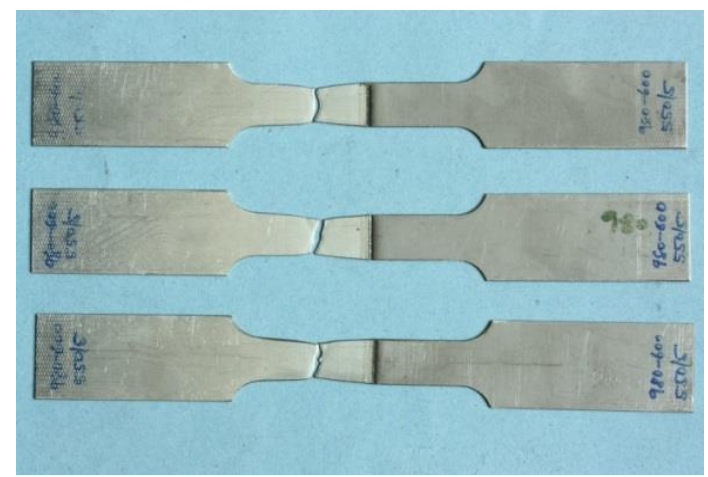

Fig. 6. Examples of the TWB specimen with the weld joint in HCT980X HCT600 combination after tensile test (welding power 550W, rate $5 \mathrm{~mm} / \mathrm{s}$ ) 
TWB was made of $1 \mathrm{~mm}$ thick sheet, consisting of dual phase steels HCT600 a HCT980X. The joint produced by laser welding has sufficient strength - the crack of the specimen in the tensile test of the weld joint was not created in the weld interface area or thermally influenced area but on the side of the steel HCT600 (Fig. 6) (Reisgen, 2012).

The weld interface position on the blank was chosen according to the expected load in the crash test and also the formability analysis of the critical area of the drawn part considering lower ductile properties of the steel HCT980X. Its properties are in Tab. 3 and 4 . In the simulation we used material model defined by the tensile test.

Tab. 3. Chemical composition of steel HCT980X

\begin{tabular}{|c|c|c|c|c|c|c|c|c|}
\hline $\mathrm{C}[\%]$ & $\mathrm{Si}$ & $\mathrm{Mn}[$ & $\mathrm{P}$ & $\mathrm{S}$ & $\mathrm{N}$ & $\mathrm{Al}$ & $\mathrm{B}[\%]$ & {$[\%]$} \\
& {$[\%]$} & $\%]$ & {$[\%]$} & {$[\%]$} & {$[\%]$} & {$[\%]$} & & \\
\hline $\operatorname{Max}$ & $\operatorname{Max}$ & $\operatorname{Max}$ & $\operatorname{Max}$ & $\operatorname{Max}$ & $\operatorname{Max}$ & $\operatorname{Max}$ & $\mathrm{Max}$ & $\mathrm{Cr}+\mathrm{Mo}<1$ \\
0.23 & 0.8 & 2.2 & 0.08 & 0.015 & 0.22 & 2 & 0.005 & $\mathrm{Nb}+\mathrm{Ti}<0.15$ \\
\hline
\end{tabular}

Tab. 4. Basic mechanical properties of steel HCT980X

\begin{tabular}{|l|l|l|}
\hline $\mathrm{R}_{\mathrm{p} 0,2}[\mathrm{MPa}]$ & $\mathrm{R}_{\mathrm{m}}[\mathrm{MPa}]$ & $\mathrm{A}_{80}[\%]$ \\
\hline 620 & 980 & 12.2 \\
\hline
\end{tabular}

The TWB shape with s marked weld interfaces is shown in Fig. 7. Blue and yellow colours signalise steel HCT600, purple one steel HCT980X.

Fig. 7. Shape and composition of the TWB

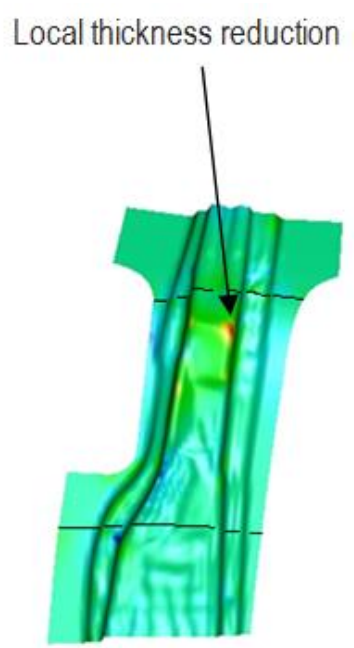

Fig. 8. Simulation of drawing of the B-pillar from TWB
Fig. 8 shows the example of the B-pillar reinforcement drawing simulation from the TWB, with marked critical area with the largest strain and local thickness reduction $(-0.11 \mathrm{~mm})$. To reduce the risk of cracks and because of significantly different strength and strain properties of steel HCT980X, we optimised size of the blankholder force on the value $200 \mathrm{kN}$ at the beginning of the drawing process and $180 \mathrm{kN}$ at its end.

Simulation of TWB drawing in FLD diagram in Fig. 9 shows a safe strain for which there are no cracks or nucleus to cracks. Similar to Fig. 5, when comparing true values of logarithmic strain in critical areas of the part drawn from TWB to strain values in FLD - diagram in Fig. 10, we can obtain technological safety given by the area of limit deformations.

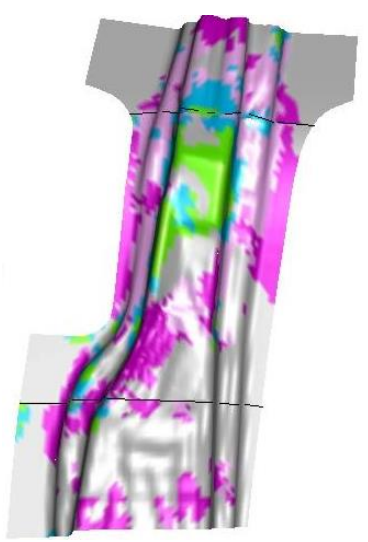

Fig. 9. B-pillar drawn from the TWB with highlighted strained areas

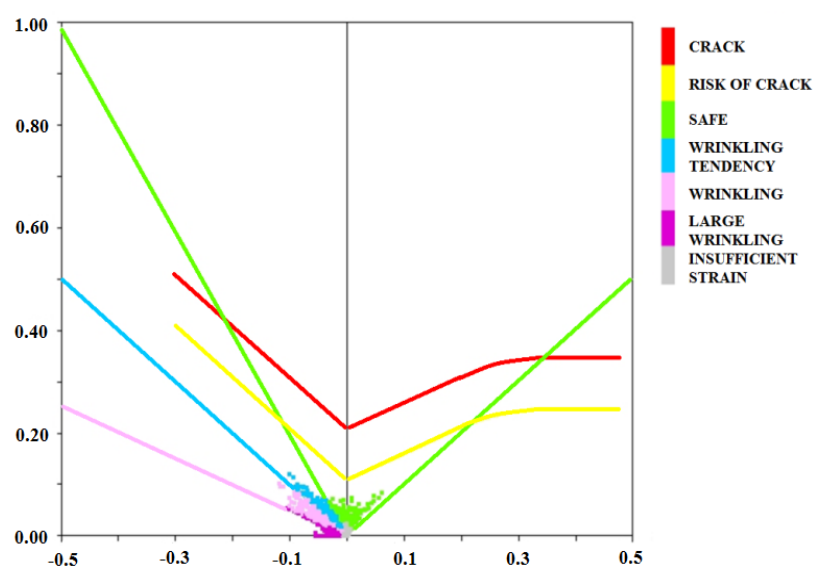

Fig. 10. Forming Limit Diagram - FLD with a color legend for the B-pillar drawn from the TWB

\subsection{Simulation of the crash tests of the drawn parts}

Analysis objective was to observe the strain properties of the B-pillar reinforcement drawn from the simple blank during crash test (side crash test of the automobile). Simulation software Dynaform (Slota et al., 2014), enabling this type of analysis, was used for definition of the position of B-pillar reinforcement with the frame on the boundary, marked with red colour in Fig. 11 and 12. Model motion rate of the deformation part with $200 \mathrm{~mm}$ diameter was $27 \mathrm{~km} / \mathrm{h}$ in the both variants. We have been observing the sizes of the reaction forces in frame areas. The size of the maximal reaction force in analysis of the drawn part from HCT600 
simple blank was $F_{R}=62.77 \mathrm{kN}$. The size of the maximal reaction force in analysis of the drawn part from TWB consisting of steels HCT980X and HCT600 was $F_{R}=61.485 \mathrm{kN}$. The time depended diagrams and sizes of the simulated crash tests in the same conditions (rate and size of the deformation part) were almost the same, the drawn parts has comparable properties (Fig.13 and 14).
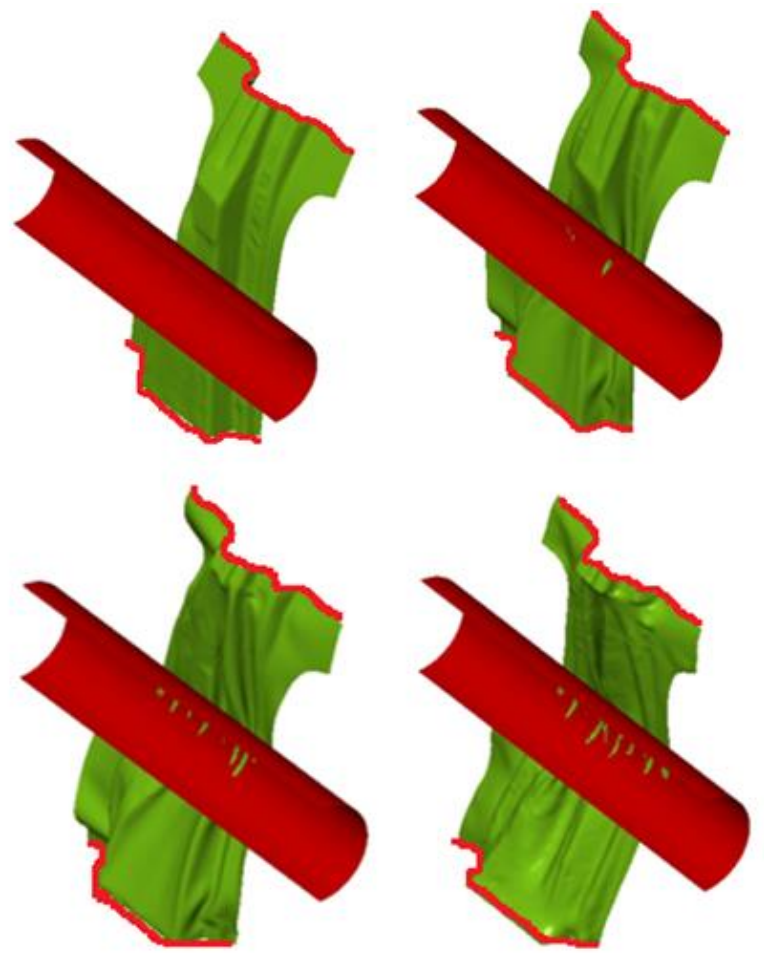

Fig. 11. Time evolution of the simulated crash of the deformation part towards drawn part from the simple blank
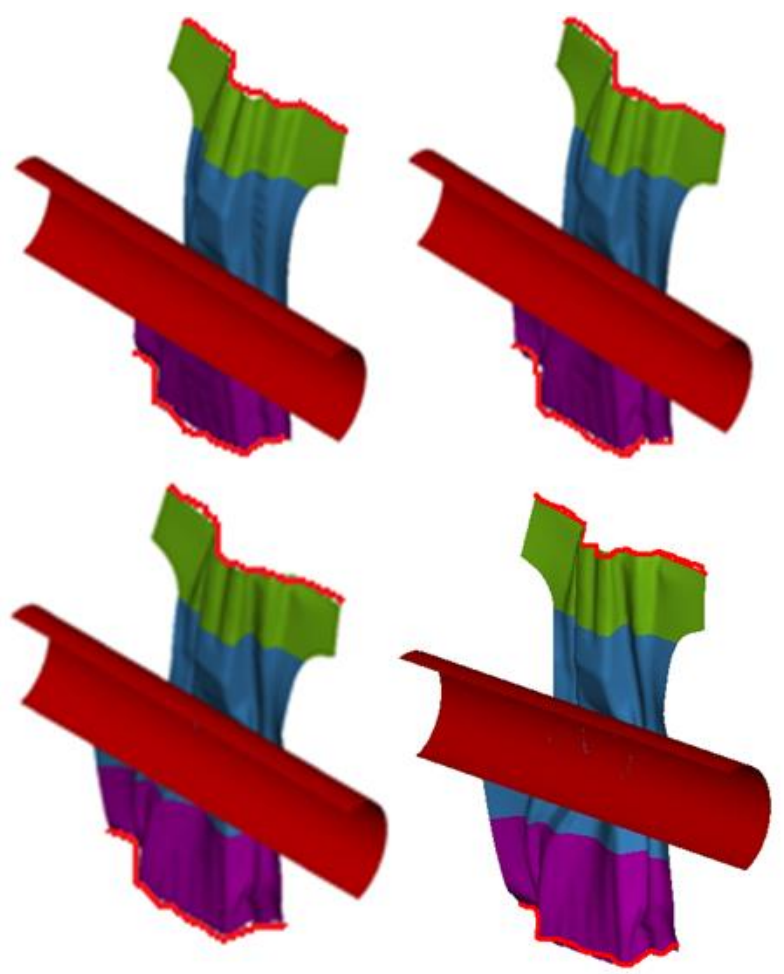

Fig. 12. Time evolution of the simulated crash of the deformation part

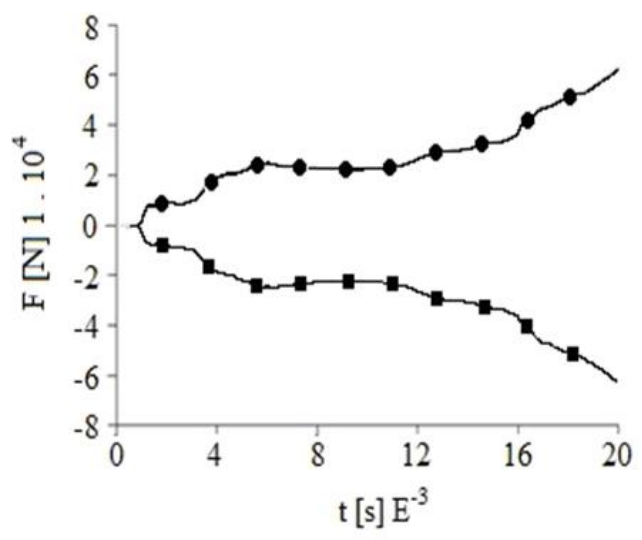

- Reaction force on the drawn part

- Force on the deformation part

Fig.13. Diagram of the reaction forces on the drawn part caused by the deformation part in simulated crash - simple blank

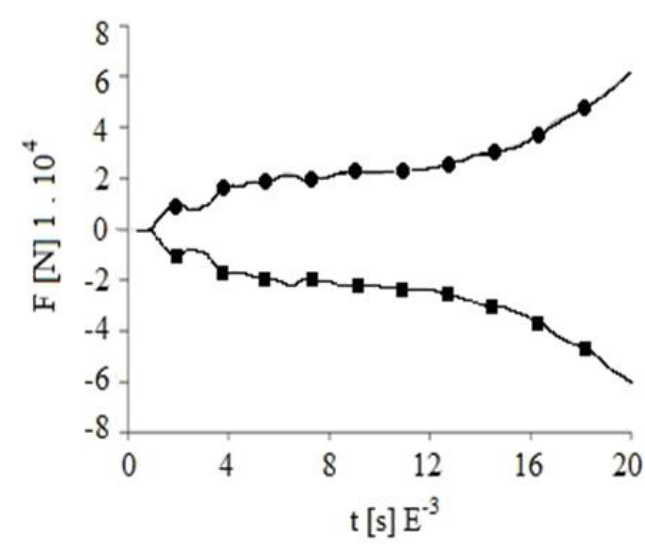

- Reaction force on the drawn part - Force on the deformation part

Fig.14. Diagram of the reaction forces on the drawn part caused by the deformation part in simulated crash - tailor welded blank

Tab. 5. The measured values of reaction forces in different time intervals with their differences

\begin{tabular}{|c|c|c|c|c|}
\hline $\begin{array}{c}\text { Measure } \\
\text { ment }\end{array}$ & Time [s] & $\begin{array}{c}\text { Simple } \\
\text { blank part } \\
\text { F[kN] }\end{array}$ & TWB F[kN] & $\begin{array}{c}\text { Difference } \\
\text { F[kN] }\end{array}$ \\
\hline 1 & 0.0018 & 7.7 & 9.97 & 2.27 \\
\hline 2 & 0.0035 & 15.785 & 15.513 & 0.272 \\
\hline 3 & 0.005 & 23.426 & 19.229 & 4.197 \\
\hline 4 & 0.007 & 23.192 & 19.247 & 3.945 \\
\hline 5 & 0.009 & 22.303 & 22.508 & 0.205 \\
\hline 6 & 0.01 & 23.076 & 23.013 & 0.063 \\
\hline 7 & 0.012 & 28.591 & 24.934 & 3.657 \\
\hline 8 & 0.014 & 32.254 & 29.593 & 2.661 \\
\hline 9 & 0.016 & 40.522 & 37.371 & 3.151 \\
\hline 10 & 0.018 & 51.647 & 46.506 & 5.141 \\
\hline 11 & 0.02 & 62.770 & 61.485 & 1.285 \\
\hline
\end{tabular}

The sizes of the reaction forces in the same time period and their differences for the both blank types are in Tab. 5 . 
The analysis of the simple blank and TWB formability using deep-drawing simulation software Dynaform on the basis of the optimisation of blank shape, blankholder force and blankholder force-displacement curve shows the possibility of the manufacturing of the chosen drawn part also with the material with higher stress and lower ductile properties in the critical area. During the manufacturing of the part by deep drawing process, we observed the local thickness reduction without any crack creation due to the sheet thickness change from 1.2 to $1 \mathrm{~mm}$.

Simulated crash test shew almost the same properties of the drawn parts from the simple blank and TWB, due to the usage of HCT 980X material in TWB in the area with the biggest bending moment. The sizes of the reaction forces in simulated frames of the drawn parts reached minimal differences for both variants. However, the sheet thickness change of the TWB from 1.2 to $1 \mathrm{~mm}$ enabled significant weight reduction of the chosen drawn part by $20 \%$.

The experiment confirmed the utilisation possibilities of modern materials and TWBs with the aim of weight reduction of steel car bodyworks.

\section{REFERENCES}

1. Bílik J., Balážová M., Kršiaková L’., Šuba R. (2010), The analyssis of properties and forming duplex steel DP 450, Hutnicke listy, Vol. 63, No. 4, 74-77.

2. Bílik J., Ertel J., Bárta J., Marônek M., Šugárová J. ( 2015), The analyssis of properties and forming of laser welded superduplex steel SAF 2507, Hutnik-WH, Vol. 82, No. 9, 627-631.

3. Chena, W., Linb, G.,S., Hub, S.,J. ( 2008), A comparison study on the effectiveness of stepped binder and weld line clamping pins on formability improvement for tailor-welded blanks, Journal of materials processing technology 207, 204-210.

4. Daxin E., Takaji M., Zhiguo L. (2008), Stress analysis of rectangular cup drawing, Journal of Materials Processing Technology, Vol. 205, 469-476.

5. Evin E. (2013), Design of dual phase high strength steels sheet for auto body, Metal $22^{\text {nd }}$ International Conference on Metallurgy and Materials, Conference Proceedings.

6. Evin E., Antoszewski B., Tomáš M., Tkáčová J., Draganovská D. (2015), Tribological Properties of Coatings for Sheet Metal Stamping Dies, Materials Science Forum, Vol. 818, 69-73.

7. Evin E., Tomáš M. ( 2012), Comparison of deformation properties of steel sheets for car body parts, Procedia Engineering, Vol. 48, 115-122.
8. Fracz W., Stachowicz F., Pieja T. (2013) Aspects of verification and optimization of sheet metal numerical simulations process using the photogrammetric system, Acta Metallurgica Slovaca, Vol. 19, 51-59.

9. Fracz W., Stachowicz F., Trzepiecinski T., Pieja T. (2014), Forming limit of the heat resistant AMS 5599 sheet metal, HutnikWH, Vol. 81, No. 7, 442-445.

10. Groche P., Metz C. (2006), Investigation of active-elastic blank holder systems for high-pressure forming of metal sheets, International Journal of Machine Tools \& Manufacture, Vol. 46, 1271-1275.

11. Kinsey L.B., Wu X. (2011), Tailor-welded blanks for advanced manufacturing. Woodhead publishing, Cambridge.

12. Merklein M., Johanes M., Lechner M., Kuppert A. (2014), A review on tailored blanks - Production, applications and evaluation, Journal of Materials Processing Technology, Vol. 214, 151-164.

13. Padmanabhan R., Baptista A.J., Olivieira M.C., Menezes L.F. (2007), Effect of anisotropy on the deep-drawing of mild steel and dual-phase steel tailor-welded blanks, Journal of Materials Processing Technology, Vol. 184, 288-293.

14. Reisgen U., Schleser M., Mokrov O., Ahmed E. (2010), Uni- and bi-axial deformation behavior of laser welded advanced high strength steel sheets, Journal of Materials Processing Technology, Vol. 210, 2188-2196.

15. Reisgen U., Schleser M., Mokrov O., Ahmedn E. (2012), Statistical modelling of laser welding of DP/TRIP steel sheets, Optics \& Laser Technology, Vol. 44, 92-101.

16. Sinha, A.K., Kim, D.Y., Ceglarek, D. (2013), Correlation analysis of the variation of weld seam and tensile strength in laser welding galvanized steel, Optics and Laser in Engineering, 51, 1143-1152.

17. Slota J., Jurčišin M., Spišák E. (2014), Experimental and numerical analysis of local mechanical properties of drawn part, Key Engineering Materials, Vol. 586, 245-248.

18. Zhong-Qin L., Wu-Rong W., Guan-Long C. (2007), A new strategy to optimize variable blank holder force towards improving the forming limits of aluminum sheet metal forming, Journal of Materials Processing Technology, Vol. 183, 339-346.

Acknowledgement: This work was supported by the Slovak Research and Development Agency under the contract No. APVV-0281-12 and by the Ministry of Education, Science, Research and Sport of the Slovak Republic under project VEGA 1/0149/13. 